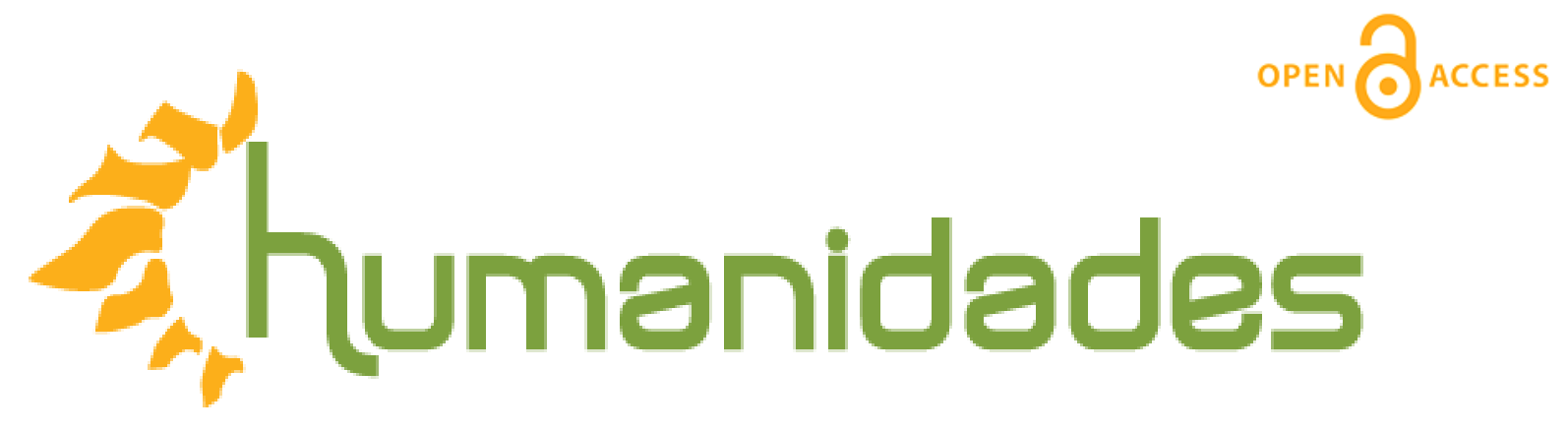

Revista de la Escuela de Estudios Generales, Universidad de Costa Rica

Julio-diciembre, 2016 • Volumen 6, número 2 • EISSN 2215-3934 • pp. 1-30

Recibido: 29-Julio-2016 Aceptado: 8-Septiembre-2016

\title{
Eva en el Paraíso: La construcción y representación del cuerpo femenino en la playa como espacio turístico en Costa Rica
}

DOI: http://dx.doi.org/10.15517/h.v6i2.26741

\section{Esteban Barboza Núñez}

Docente e investigador en la Universidad Nacional de Costa Rica. Miembro de la Red de Investigación en Turismo, Sociedad y Ambiente, de la Universidad Nacional; y coordinador de la Cátedra Antonio Maceo, de la misma institución.

Correo electrónico: ezteban@ @otmail.com

Todos los derechos reservados. Universidad de Costa Rica. Esta revista se encuentra licenciada con Creative Commons. Reconocimiento-NoComercial-SinObraDerivada 3.0 Costa Rica.

Correo electrónico: humanidades@ucr.ac.cr / Sitio web: http://revistas.ucr.ac.cr/index.php/humanidades 


\title{
Eva en el Paraíso: La construcción y representación del cuerpo femenino en la playa como espacio turístico en Costa Rica
}

\section{Resumen}

El artículo analiza la representación del cuerpo femenino como destino turístico, en la promoción de las playas en Costa Rica. Se hace un esbozo del estatus de la figura femenina en el imaginario androcéntrico occidental, desde sus raíces judeocristianas y de pensamiento clásico, hasta el advenimiento de la modernidad. Se reseñan postulados acerca del estatus del cuerpo femenino y la forma en que se construye en las representaciones gráficas; se parte de que la manera en que el cuerpo femenino es representado en la publicidad, enfocada a atraer turistas a la playa, le genera una doble otredad. La primera como mujer, cuyo físico es controlado por un imaginario androcéntrico que lo usa cual Eva-sirena, que tienta y atrae al posible visitante. La segunda como elemento que recrea una fantasía de exploración colonial de una playa prístina y "virginal", y que la aleja de la modernidad racional cartesiana, en la cual la mente se impone a un cuerpo que debe ser controlado y domesticado por la razón.

\section{Eve in Paradise: The Construction and the Representation of the Female Body on the Beach as a Tourist Attraction in Costa Rica}

\begin{abstract}
The article analyzes the representation of the female body in the advertisement industry of the beach as a touristic destination in Costa Rica. The paper starts with a survey of the status of the female body in Western androcentric thought, since its Judeo-Christian and classical roots, to the advent of modernity. There is also an analysis of the way the female body is constructed in graphic representations, and the main thesis states that the ads intended to attract tourists to the beach and in which the female body appears generate a double othernes in women. First, as females with bodies controlled by an androcentric worldview that uses them as Eve-Mermaids that tempt and attract the potential visitor. The second one, as an element that recreates a fantasy of colonial exploration of a "virgin" beach, and that takes the bodies away from Cartesian racionality, in which the mind rules over a body that must be controlled and domesticated by reason.
\end{abstract}

\author{
Keywords: Tourism, \\ Costa Rica, feminism, \\ gender stereotypes, \\ iconography.
}

Palabras claves:

Turismo, Costa Rica, feminismo, estereotipo sexual, iconografía. 
A pesar de haber sido sinónimo de turismo de naturaleza y ecoturismo, durante la última década del siglo XX, Costa Rica, a partir del siglo XXI, comenzó una diversificación de la oferta turística que, entre otros destinos, impulsaría el sol y la playa como focos de atracción, tanto para los visitantes, como para la inversión extranjera. La concepción y el desarrollo de polos turísticos en provincias como Guanacaste y Puntarenas, a partir de mediados de la década de los ochenta y principios de los noventa, los cuales se enfocaron en turismo residencial y hoteles todo incluido; y la construcción e inauguración de un aeropuerto internacional en la ciudad de Liberia en 1995, son claros ejemplos del impulso que se le dio a este tipo de actividad turística. La noción del paraíso verde ecoturista, ampliamente difundida a través de campañas publicitarias y marcas país, durante la última década del siglo anterior, empezó a fusionarse con el destino del sol y la playa, con un turismo más evasivo y hedonista; de ahí que muchos lugares comenzaron a promocionarse como una mezcla de ambos.

Una de las características principales de la promoción turística de la playa en Costa Rica, específicamente en el ámbito gráfico, es el impulso de un imaginario prístino, virginal, en el cual parajes edénicos, cuidadosamente descontextualizados y con poca o ninguna huella humana, especialmente local, aguardan al turista. Esta descontextualización y esta sistemática ausencia de rastros de pobladores y cultura local en las representaciones gráficas obedecen 
a un tipo de narración que acerca los destinos descritos y recreados a parajes imaginados, típicos de fantasías coloniales de descubrimiento y exploración. En estos últimos, lo prístino está por ser hallado y disfrutado por un advenedizo visitante que hace las de aventurero explorador.

Lo virginal y lo despoblado de las imágenes representativas es, de vez en cuando, interrumpido por la incursión del cuerpo femenino como elemento humano implantado cuidadosamente en el paraíso tropical. A partir de un análisis de la construcción y del posicionamiento de los cuerpos femeninos insertados en dichas imágenes, tanto en publicidad oficial como en guías de viajes populares y algunas de las más conspicuas páginas web acerca de estos destinos en Costa Rica, se puede trazar un modo de representación que devela una doble otredad femenina a partir de cómo esos cuerpos aparecen. Primero como mujer, cuyo físico es controlado por un imaginario androcéntrico que lo usa cual Eva-sirena, como anzuelo que tienta y atrae al posible visitante. Segundo, como un elemento más de un paisaje, el cual recrea una fantasía de exploración colonial y que, al hacerla parte de este, la aleja de la modernidad racional cartesiana, en la cual la mente se impone a un cuerpo que debe ser controlado y domesticado por la razón que sobresale en la ideología y en la naturaleza de un turismo que parte de un primer mundo metropolitano y racional, a un supuesto paraíso tropical salvaje, prístino e indolente. 
Las principales tendencias del pensamiento moderno, ya sea desde sus raíces en la teología judeocristiana, en el pensamiento del mundo clásico o en la filosofía y la ciencia, posteriores al Renacimiento, han construido una feminidad sujeta, desde justificaciones teológicas, filosóficas y científicas, a un androcentrismo prevalente y definitorio de su estatus y función social. En la teología judeocristiana, se advierte la sustitución de abundantes deidades femeninas, junto con otras masculinas, por un dios varón, único y dominante en la figura de Yahvé. Esta figura emergente no solo negaría la existencia de divinidades femeninas, sino que también ayudaría a relegar a la mujer a un estatus de otredad, devenida del hombre y subordinada a este dentro de la familia, con funciones especializadas como proveer herederos legítimos, criar niños pequeños y llevar a cabo labores domésticas (Lipsitz, 1993).

En el pensamiento griego, otro pilar de la futura epistemología moderna, Platón, por ejemplo, les negaba a las mujeres el derecho de poseer propiedades, heredar y atestiguar en Cortes de ley, mientras las relegaba a labores domésticas, la procreación y el cuidado de niños. Aristóteles va más allá y las define a partir de sus deficiencias e incapacidades en relación con el hombre; para él, la función de la mujer será facilitar a sus superiores masculinos una vida racional, deliberativa y ordenada (Lipsitz, 1993).

\section{El cuerpo}

femenino y su

sujeción al control patriarcal 
Ya dentro de la modernidad, y a propósito del cuerpo, se difunde un esencialismo biológico con bases racionales, las cuales le otorgan al cuerpo femenino funciones específicas que, con la sanción de la ciencia y la razón modernas, las relega al mismo estatus de los periodos clásicos o al otorgado por la teología judeocristiana. Herbert Spencer (1852) concluye que la existencia de divisiones de clases y de funciones laborales, según el sexo, obedece a un orden biológico; por lo tanto, la biología es la que moldea los sexos para cumplir labores específicas dentro del conglomerado social.

En la sociobiología decimonónica, la cual traslapa comportamientos animales y humanos, también se advierte que por naturaleza los machos son promiscuos, violadores y que abandonan a sus parejas y a sus crías; de esta forma, pueden asegurarse el mayor número de hembras y transmitir el mayor número de genes. El animal de sexo femenino, por otra parte, y en su defecto las mujeres, son castas hasta encontrar la mejor pareja sexual, ya que al tener menores posibilidades de reproducirse, aguardan hasta el momento propicio para hacerlo con el macho indicado (Lipsitz, 1993). Es decir, se compara y se equipara el comportamiento de algunas especies animales con el que supuestamente "por naturaleza" se espera de los humanos, relegando a las mujeres y a sus cuerpos a un plano convenientemente sujeto al androcentrismo. 
Teóricos más recientes, como Pierre Bourdieu, cuestionan ese modo "naturalizado" de ver la biología como condicionante, por sí sola, del comportamiento y la función social del cuerpo, según la clase y el género. Para Bourdieu, la identidad natural es en realidad un tipo de identidad social vista como natural y "casi no es necesario recordar en efecto que el cuerpo, en lo que tiene de más natural en apariencia, es decir, en las dimensiones de su conformación visible, es un producto social" (1986, p. 184). Por lo tanto, las características supuestamente naturales otorgadas por la naturaleza a cada sexo, y que los precondiciona a ciertas funciones sociales, no son más que constructos derivados de mecanismos totalmente trazables y deconstruibles, por ejemplo el androcentrismo, pero que se presentan y se difuminan como naturales e incuestionables.

Lo anterior concuerda con la célebre frase de Simone de Beauvoir de "la mujer no nace, se hace", la cual indica que la identidad femenina está instituida en una repetición estilizada de actos (2010, p. 24). En ese sentido, Judith Butler sostiene que "significativamente el género es instituido por actos internamente discontinuos, [y que] la apariencia de sustancia es, entonces, precisamente eso, una identidad construida, un resultado performativo llevado a cabo [de modo] que la audiencia social mundana, incluyendo los propios actores, ha venido a creer y a actuar por creencia" (1993, p. 297). Es decir, a partir de actos y comportamientos condicionados, se crea una especie de naturalidad que 
los da por sentados e incuestionables y que irremediablemente situarán al cuerpo femenino bajo control de una razón masculina que es, al mismo tiempo, su antítesis.

Según estos casos, es a partir de la herencia del pensamiento clásico y la influencia de la teología judeocristiana en la modernidad occidental, pasando por la influencia y el posicionamiento del discurso científico moderno, sustentado por la cuasi incuestionable razón cartesiana, que el cuerpo femenino ha ido adquiriendo el estatus de un otro al intelecto masculino, el cual lo escruta, lo reproduce y le otorga un lugar, según los intereses hegemónicos prevalentes. Como apunta Flavia Rando (1991), en la cultura occidental, el conocimiento femenino y su creatividad han sido entendidos dentro de los confines de la ideología de género que identifica a las mujeres con el cuerpo sexual y reproductivo; ellas y sus cuerpos se asocian con la naturaleza y no con la cultura.

Esta asociación puede ser vista, en la cultura occidental, como fuente de una construcción particular asimétrica de categorías "mujer" y "hombre", asimismo, como la subyugación de las mujeres en el contrato social. La relación de las mujeres con lo natural a menudo ha causado que el conocimiento femenino y su representación surjan de modo esencialista; es decir, entendido y evaluado como un retorno a lo natural, en vez de expresar conocimiento generado desde una 
posición específica dentro de la cultura -una que media incluso las experiencias del cuerpo-.

Así las cosas, de acuerdo con el modelo cartesiano cogito ergo sum, si las mujeres son más cuerpo que mente, ellas, representadas por su físico y por su función natural, van a quedar desprovistas de la racionalidad de la mente pensante, en este caso, vindicada por el género masculino que razona y ordena. Entonces, van a alejarse de la razón y a situarse próximas a lo irracional y a lo natural.

Ahora bien, el cuerpo femenino en la producción gráfica y en el arte, según los cánones prevalentes en los modelos occidentales, ha sido siempre representado como un objeto, en ese sentido, rara vez se reconoce como sujeto de la producción cultural por derecho propio. A pesar de la abundancia de cuerpos femeninos en la cultura visual, la representación de la subjetividad femenina, su conocimiento, experiencia y contribución han sido enormemente excluidos de una historia del arte visual dominada, en su mayoría, por hombres ('Pro'Sobopha, 2005). Es más, el arte mismo es un dominio del hombre y el papel de la mujer en la pintura es el de modelo o musa (Carson, 2000). Se refuerza, entonces, en la producción gráfica y el arte canónico occidental, la idea del androcentrismo y la otredad de la mujer, cuyo cuerpo sujeto a la autoridad patriarcal, como única carta de 
presentación, la condiciona a una otredad que, a su vez, la aleja de la producción de saber, la autonomía y la voz propia.

Al trasladar estas nociones acerca del estatus y la representación, así como la supuesta función del cuerpo femenino en los cánones filosóficos y científicos modernos, a un área como la publicidad turística, se deben aclarar algunas nociones sobre la naturaleza de un turismo de este tipo, sol y playa, y su relación con prácticas como el colonialismo y el modelo de enclave. Este tipo de turismo, el cual se centra en explotar el espacio costero como lugar de atracción, sigue un modelo que en ocasiones ha sido cuestionado por establecer mecanismos de producción y distribución de la riqueza, así como de uso del espacio, que más bien enfatizan desigualdades entre inversionistas, desarrolladores, turistas y habitantes locales.

Para algunos estudiosos de la actividad turística, desde la década de los noventa del siglo pasado (Molina y Rodríguez, 1991), el turismo en América Latina es visto como una manifestación de las relaciones desiguales entre países desarrollados y países subdesarrollados, la cual sigue la lógica de la capacidad de acumular capital de los primeros, con los recursos naturales explotables, como única carta de presentación, de los segundos. En cuanto al desarrollo del turismo de sol y playa, existe la tendencia a establecer modelos de enclave en las zonas con aptitud geográfica y climática para este tipo de turismo, 
con la particularidad de que el modelo llega a constituir unidades de ocio privatizadas e independientes de los territorios donde se instalan; es decir, se constituyen burbujas o enclaves turísticos (Aledo, 2008).

En el caso costarricense, específicamente en lugares que han apostado por este tipo de turismo, como Guanacaste y el Pacífico Central, se han seguido parámetros que en muchas instancias emulan la tendencia dada en otros países latinoamericanos. Las grandes cadenas hoteleras transnacionales invierten, desarrollando inmuebles de su propiedad y adquiriendo grandes extensiones de territorios litorales, incluidos sus recursos naturales, como bosques y agua, para su uso exclusivo; posteriormente, redirigen las ganancias al exterior. Es decir, existe un paralelismo entre su funcionamiento y el modo de operar de enclaves anteriores, de tipo bananero y minero, antes o después de la era colonial. En muchos casos, se saca provecho de la desregulación que impera sobre los mercados de suelo y de las debilidades institucionales para gestionar los desafíos que representan para los territorios locales. De esa forma, estos consorcios se asientan sobre territorios donde prevalecen grandes problemas de pobreza y exclusión social y donde existen importantes riquezas naturales, poca organización social de base y débiles gobiernos locales (Román, 2011). 
Al ver la lógica de este sistema de explotación, primero, se "descubre" un determinado territorio relativamente virgen, desde la perspectiva de la industria, después, surge progresivamente la explotación comercial masiva. Más tarde, este destino se masifica, pierde su novedad y empieza a degradarse. A este punto, el lugar se reconvierte y se reinventa; entra en una fase de decadencia. Paralelamente, el capital empieza a fugarse hacia otros destinos "por descubrir" (Cañada, 2011).

Según las características antes mencionadas, expuestas por estudiosos del turismo en América Latina, se podría argumentar que realmente se trata de una explotación con grandes similitudes al modelo colonialista. En ese sentido, un capital extranjero enclaviza una producción local, no necesariamente para beneficio del lugar donde se instala, sino más bien para favorecer al inversionista foráneo. Se da, por lo tanto, una relación de poder desigual entre el capital metropolitano que "descubre" y "explora" y una periferia que tiene como carta de presentación los recursos naturales y la mano de obra, con la cual puede echar a andar el proyecto ideado e implementado desde afuera, con el apoyo de las élites locales.

En definitiva, nada de lo dicho anteriormente puede ocurrir sin una debida justificación ideológica y sin el impulso de aparatos hegemónicos que sustenten. De esa manera, los procesos serán vistos, al menos por la mayoría, como causas comunes, normales, incluso, 
necesarias y de gran ayuda para el comercio y la economía local. Es en este punto donde el análisis de la narración y la representación del espacio, de los sujetos locales y de las prácticas turísticas dadas, es de fundamental importancia para, precisamente, entender la naturaleza y las consecuencias de un turismo como el de sol y playa; asimismo, para comprender el modo en el cual el cuerpo femenino es utilizado en la promoción de este tipo de actividad.

Diferentes teóricos del turismo se han dado a la tarea de analizar, desde la perspectiva de los estudios postcoloniales, la decolonialidad, la antropología y otras ciencias sociales, la relación que existe entre turismo y colonialidad. En cuanto a la representación y la narración del espacio y de los sujetos nativos de áreas turísticas en países latinoamericanos, africanos y asiáticos, Charlotte Echtner y Pushkala Prassad (2003) sostienen que los modos en que se presentan refuerzan tres mitos coloniales que perpetúan la construcción del espacio turístico y de sus pobladores como el otro del inversionista y visitante extranjero.

El primer mito tiene que ver con lo inalterado, con lo que no cambia, con ese paisaje y ese mundo que permanece enclavado en el ayer y cuya visita supone para el turista un viaje en el tiempo, siglos atrás, al mejor estilo de los exploradores, cazadores de tesoros, arqueólogos y aventureros coloniales. Se espera que el turista cumpla el papel de explorador, 
descubridor o comerciante, por lo que, el destino debe representarse como si no hubiera sufrido cambios, a pesar del paso de los siglos.

De acuerdo con estas autoras, el segundo mito es el desenfreno. Este se relaciona, sobre todo, con los destinos turísticos que combinan el sol, la arena y las construcciones de lujo, las cuales invitan al visitante a ser autoindulgente y a considerar que los recursos del lugar se encuentran a su total disposición para satisfacer todo tipo de placeres sensoriales. En ese sentido, los turistas tienen acceso total a la abundante naturaleza, cuentan con una infraestructura bien equipada y con anfitriones serviles; se trata de un modo de utilización de los recursos que se asemeja a una visión romantizada del colonialismo. Al igual que en el mito anterior, los habitantes locales, sus condiciones de vida, sus lugares de habitación y sus medios de producción son obviados, lo mismo sucede con aquellos componentes del paisaje que no están relacionados con el idílico resort de lujo o con la playa prístina que se requiere promocionar (Echtner y Prassad, 2003).

El tercero, el cual a efectos de este trabajo interesa mucho, es lo incivilizado. De acuerdo con este mito, el turista viaja a lugares primigenios donde la civilización está casi completamente ausente y la naturaleza es salvaje. El paisaje es supuestamente virgen, cubierto de vegetación inhóspita que alberga animales extraños y peligrosos; por lo tanto, es perfecto para que el turista se embarque en viajes de 
descubrimiento y reviva, de esa manera, la nostalgia del explorador colonial. En muchos casos, la razón principal que motiva a preservar la naturaleza en estos parajes es, precisamente, que pueda ser visitada y “descubierta” por el turista-explorador (Echtner y Prassad, 2003).

Estos mitos, en la representación del espacio turístico y sus pobladores nativos, establecen oposiciones binarias entre quien narra y representa, y entre quien es narrado y representado. Por ejemplo, el progreso frente al atraso; el avance frente al estancamiento, lo industrializado y lo subdesarrollado; la disciplina y la racionalidad frente al desenfreno, la relación entre un amo que es servido y un siervo cuyo propósito es brindar servicio al amo; y, finalmente, lo civilizado frente a lo salvaje.

En cuanto a la representación de las mujeres en la publicidad turística, en países que dependen de esta actividad para su desarrollo, se nota una combinación entre de los postulados patriarcales acerca del estatus y uso del cuerpo femenino y el colonialismo de las imágenes y la narración y representación del espacio turístico. Indra Munshi (2006), por ejemplo, sostiene que en los países donde se utiliza el turismo como estrategia de desarrollo, la mujer es vista como objeto de atracción de la mirada masculina, tanto local como extranjera. De esa manera, muchos de esos países han adquirido la reputación de ser "periferias de placer" para el turista proveniente de metrópolis europeas y estadounidenses. Asimismo, la autora afirma que esto no solo ocurre 
con las mujeres, sino que los paisajes y los lugares también son exotizados y sexualizados, cargados con atributos femeninos cuyo propósito es atraer y complacer la mirada masculina. Ejemplo de lo anterior es la "playa virginal" (Munshi, 2006).

Otros autores, como Pritchard y Morgan (2000), afirman que el lenguaje y las imágenes de la promoción turística privilegian la mirada masculina y heterosexual. Las representaciones de los hombres en la publicidad tienden a estar asociadas con la acción, el poder y la posesión; mientras que las representaciones de las mujeres tienden a relacionarse con la pasividad y la disponibilidad de ser poseídas. En este punto, se percibe claramente la combinación de la mirada colonialista, la narración y representación del espacio, las actividades turísticas como complacedoras de una actitud de supuesto descubrimiento y exploración, y la mujer, su cuerpo y su representación, como parte de ese paisaje y ese destino, sujeta al control patriarcal, a su uso y posesión.

Es interesante notar que estos modos de representación del destino turístico, en este caso la playa, y la construcción y exposición del cuerpo femenino están tan afianzados en el imaginario, tanto local como en los contextos metropolitanos hacia los que se dirigen, que son aceptados y vistos como normales y como totalmente aceptables. La publicidad, en la mayoría de los casos, trata de articular los ideales de una clase media y provee una ventana de concepciones convencionales y predominantes 
acerca de lo que se oferta, muchas veces, tratando de no ofender a la audiencia. Por lo tanto, lo que se anuncia, y el modo en que se anuncia, a menudo concilia con los valores y símbolos básicos que tienen vigencia cultural (Lynch, 2005). Además, la publicidad moldea la forma en la que la gente percibe la realidad, a través de lo que Mikhail Bakhtin (1981) llamaría desempeño ideológico; puesto que convergen la cultura, la ideología y, en este caso, la percepción del género, en una o varias sociedades. Puntalmente, la mujer se presenta como ente mercantilizado, disponible y alejado de la razón.

Comentados algunos conceptos básicos sobre las ideas patriarcales del cuerpo femenino; las principales características del modelo turístico del sol y la playa, y su relación con la colonialidad; y la crítica a las nociones y representaciones del espacio turístico y

Representación del cuerpo femenino en la playa costarricense la mujer como mercancía para atraer al turista, es posible analizar concretamente algunas representaciones reales de la mujer en el sol y en la playa de Costa Rica.

Resulta necesario aclarar que la muestra no pretende ser exhaustiva, sino meramente cualitativa. Es decir, no se trata de agotar los ejemplos que puedan surgir, sino más bien de una búsqueda en sitios representativos y con mayor afluencia de usuarios. Para lo anterior, se utilizan motores de búsqueda como Google, a partir de palabras claves como "Costa Rica", "playa" y "sol”, entre otras; guías de 
viajes reconocidas, tanto locales como extranjeras; y páginas que promueven turismo y actividades ligadas a la playa, en los principales destinos del país.

Al realizar la búsqueda con palabras claves en español, inglés, francés, alemán e italiano, la gran mayoría de fotografías, en la sección de imágenes del motor de búsqueda, muestran playas "virginales" cuidadosamente despobladas y descontextualizadas de sus entornos y alrededores.

En primera instancia, cuando se utilizan palabras en inglés aparecen 320 fotografías. Una gran parte de estas, alrededor de 160, ilustra el mar, la playa y la naturaleza circundante, no aparecen personas ni construcciones. Así pues, se percibe un meticuloso destierro de todo trazo humano, ya sean bañistas o habitantes locales, lo cual acentúa el mito de lo prístino y refuerza la idea de vincular el destino de sol y playa con el turismo de naturaleza y aventura, característico de Costa Rica. No sucede lo mismo con otros destinos, como Cuba y República Dominicana, donde una búsqueda similar despliega imágenes con menos naturaleza, en las que se observan más bañistas y vacacionistas, y, sobre todo, grandes resorts; por lo tanto, se alejan de la fantasía del retorno a la naturaleza y se acercan, como destinos, al mito del desenfreno. 
En la búsqueda sobre Costa Rica, son pocas las imágenes que muestran resorts y hoteles, en comparación con otros países; nos obstante, propiamente en el ámbito costarricense, este tipo de edificaciones supera cualquier otra construcción retratada en las playas. Lo anterior refuerza la idea de que dichas instalaciones están ahí para el turista y que este puede disponer de sus recursos y sus atractivos. Con respecto a la aparición de personas en las fotografías, se obtienen 15 imágenes con planos abiertos en los que no es posible distinguir los rostros y contornos de las personas, aunque queda claro que son vacacionistas. En ningún caso los planos abiertos muestran números masivos de personas, como podría suceder en temporadas altas, cuando las playas suelen llenarse de visitantes locales, lo cual da la impresión de que aun cuando puede haber gente en las playas, sus números nunca son masivos; de esa manera, el destino siempre guardará naturaleza y exotismo para el visitante.

En 32 fotografías se puede distinguir claramente el sexo de quienes aparecen. Así, en 26 imágenes se observan mujeres; en 5 una pareja, es decir, un hombre con una mujer; y solamente en 2 fotografías se capturan hombres. Estas últimas ilustran a personajes masculinos practicando surf: en una el hombre se desplaza sobre una ola y en otra corre hacia el agua con la tabla bajo el brazo. 
De las 26 imágenes en las que aparecen mujeres, solo en un caso se ejecuta una acción. Se trata de una fémina que es fotografiada, de espaldas, mientras lucha por atrapar un pez vela que sale del agua; esto con ayuda de su caña de pescar. En los otros retratos, las mujeres no realizan actividad alguna, aparecen como adornos que decoran la playa; ya sea acostadas tomando el sol, en pose de modelaje sonriendo a la cámara, de espaldas mirando hacia el mar o sujetando tablas de surf, como los hombres. Estas tablas, no obstante, solo se usan como accesorio para retratarse, pues se percibe que están posando para la cámara y no llevan a cabo una acción, a diferencia del hombre que se desliza sobre una ola y que, probablemente, no se percata de que está siendo fotografiado.

En una de las fotografías mencionadas anteriormente, se observa a una mujer detrás del lente de una cámara que descansa sobre un trípode; ella misma está posando para esta cámara, lo cual transforma en una modelo a una posible retratista. Algunas imágenes, en las cuales podría argumentarse algo de acción, muestran a las mujeres de pie, con los brazos extendidos al aire (como si trataran de recibir a alguien), percibiendo el olor de una flor, ejecutando alguna postura de yoga o un paso de baile. Claramente, se percibe un propósito: ser retratadas como parte del paisaje y no como ejecutoras de una acción. 
Ahora bien, en relación con las imágenes en las que se observan parejas, se puede decir que en todos los casos el hombre se ubica frente a la mujer o aparece abrazándola desde atrás. Lo anterior denota control por parte del personaje masculino y remite a la mujer a la pasividad y a la sumisión. Las búsquedas realizadas en español, francés, italiano y alemán arrojaron resultados bastante similares.

Las páginas que funcionan como promotoras de lugares específicos, actividades y negocios brindan un panorama semejante, en algunos casos, incluso, las imágenes resultan más elocuentes. La popular página www.travelcostarica.cr es una de las guías más consultadas, esta usa la marca país essential Costa Rica y se promociona en cinco idiomas. En la sección de actividades de playa, la foto de portada muestra una playa de arena blanca, con el mar a la derecha y una extensa vegetación a la izquierda, sin rastros de construcciones; en el centro, aparecen tres mujeres jóvenes tomando el sol, en bikini, y una caminando en la playa.

Otra página bastante conocida es www.visitcostarica.com. Se trata de una vitrina promocional del Instituto Costarricense de Turismo (ICT), en la cual se expone una inmensa galería de fotos que ilustran sitios de interés y actividades que se pueden realizar en todo el país. De todas las imágenes, 45 muestran playas, en la mayoría, las riberas aparecen desiertas y son tomadas desde planos abiertos; sin embargo, en 8 casos se identificaron personas fotografiadas de lejos. 
Algunos son bañistas, otros surfistas (de ambos sexos) y otras, con mayor detalle y en mayor cantidad (3), mujeres en medio de la nada. Ellas, al igual que en la búsqueda general en Google, no realizan acciones (en ninguna de las tres fotografías); yacen en la playa o están de pie, en el centro de la imagen.

En cuanto a las iniciativas locales de promoción, la dinámica parece repetirse, en algunos casos, incluso, la mercantilización del cuerpo femenino se hace más explícita. Por ejemplo, la página promocional de Montezuma, en la península de Nicoya, muestra en su portada a una mujer tendida boca arriba en la arena, con los brazos abiertos (de nuevo, como si tratara de recibir a alguien); en una posición que denota pasividad, sumisión y receptividad.

El sitio que difunde la actividad de Santa Teresa, también en la península de Nicoya, publica en su portada a una mujer; en este caso, se observa de pie, con los brazos extendidos y denotando una presteza a recibir y abrazar a quien la mira, no hay nadie más a su alrededor. En tanto que, la página de información www.playascostarica.info se presenta en idioma inglés y muestra imágenes de las principales playas del país. En la sección de Manuel Antonio, famoso parque nacional del Pacífico Central, conocido mundialmente por su exuberante naturaleza, se muestra solo la fotografía de una mujer que descansa en la playa, sobre sus codos y con las piernas entreabiertas. No se alcanza a ver nada 
Eva en el Paraíso: La construcción y representación...

más, únicamente la arena sobre la que posa y una minúscula porción de agua; se deja por fuera todo lo que, en apariencia, hace famosa a la playa y a sus alrededores.

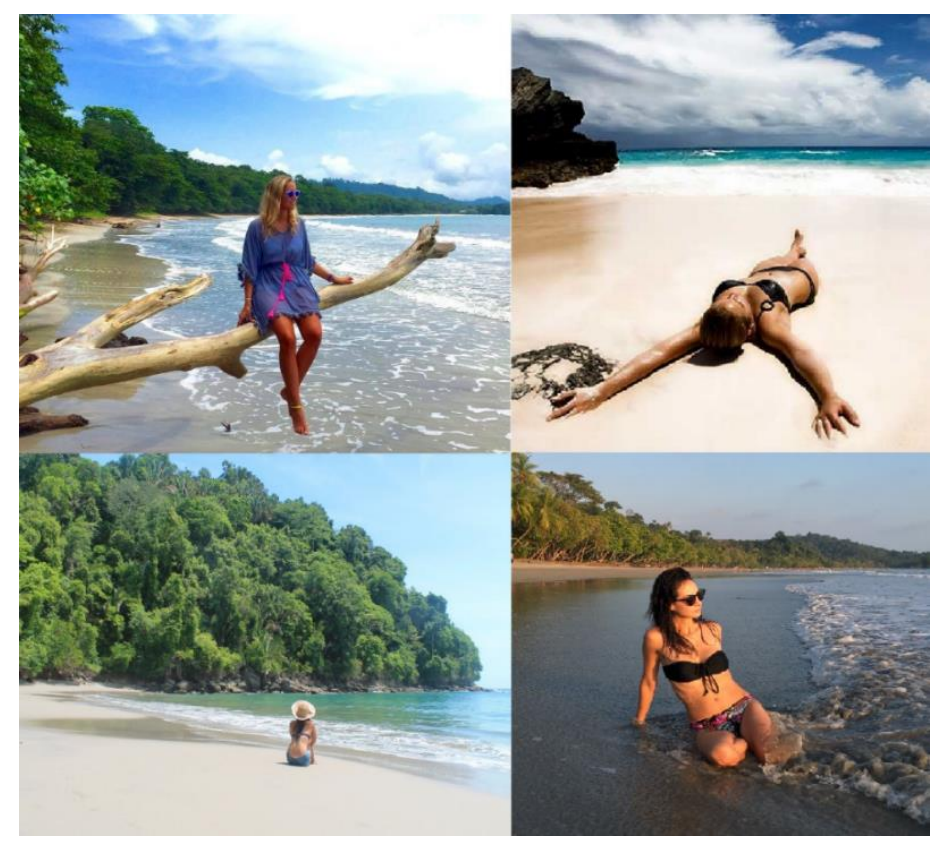

Figura 1. Mujeres adornando el paisaje para promocionar playas costarricenses. De izquierda a derecha: Cahuita (Limón) y Montezuma (Puntarenas). Inferiores: Manuel Antonio, Puntarenas. Se puede advertir la función puramente decorativa, como elemento que se mimetiza con lo primigenio del paisaje. En el caso de las dos fotografías de la derecha, se observa el lenguaje corporal pasivo y receptivo de las modelos.

Existen, además, otras páginas web que divulgan información sobre el país, no necesariamente con el propósito de atraer turistas 
por unos cuantos días. Estos, al igual que los sitios analizados líneas atrás, tienden a usar el cuerpo femenino como señuelo decorativo que acompaña los textos, aun cuando estos no se vinculen directamente con la playa. Ejemplo de lo anterior son los sitios de bienes raíces, como www.palmsrealtycr.com, donde se ofertan propiedades para rentar y alquilar en el país. La página principal dicho sitio, curiosamente, no exhibe inmuebles, sino la fotografía de una mujer en la playa, tendida en una hamaca, con un lenguaje corporal que denota pasividad, indolencia y, como en otros casos ya mencionados, receptividad a la mirada masculina.

En revistas prestigiosas, como Forbes, también se observa este recurso. Por ejemplo, en su página de noticias aparece una lista con las "diez mejores playas del Caribe", entre estas se encuentra Cahuita, la provincia de Limón. A la leyenda descriptora de un renglón y medio, se le suma la fotografía de una mujer sentada sobre la rama de un árbol caído; ella mira hacia el mar, en apariencia desentendida del lente, pero claramente se percibe que posa para este. $\mathrm{Al}$ fondo aparece, en un segundo plano, la playa enclavada en el Parque Nacional Cahuita, y, en un tercer plano, el caserío de ese lugar, solo reconocible para quien haya estado en el lugar, debido a la lejanía desde la cual se toma la foto.

Esta situación también se presenta en páginas de noticias sobre turismo, como el sitio www.ticovision.com, donde, por ejemplo, se 
exponen datos acerca de los ingresos de esta actividad en la región, los cuales constituyen, en promedio, el 30 por ciento del PIB de la mayoría de los países. Si bien la noticia se respaldada con datos duros de la Comisión Económica para América Latina y el Caribe (CEPAL), llama la atención que esta se ilustre con una fotografía que muestra a tres mujeres aplicándose bronceador en la playa, en poses típicas de modelaje.

Se encuentran, asimismo, algunos sitios más explícitos que promueven un turismo de evasión, entre estos, www.puravidabachelorparties.com. La gran mayoría de las ilustraciones que se utilizan en esta página involucran a mujeres que posan, de manera sensual, en las playas. De esa manera, se persuade la mirada de un hombre heterosexual que busca de diversión y hedonismo en la paraíso tropical.

Después de contrastar la teoría básica sobre el estatus del cuerpo femenino como objeto de un mundo ideado desde el androcentrismo, con la idea del destino turístico tropical como una extensión en tiempo de fantasías coloniales a nivel imaginario y a nivel de explotación y uso de recursos, la impresión que queda es que en realidad existe una doble otredad del cuerpo femenino en cuanto elemento promocional de la playa como destino turístico. Así pues, como Walter Mignolo sostiene, no puede haber modernidad sin colonialidad (2007), aunado a esto, se podría decir que el patriarcado 
es también un constituyente primordial de esta. Es, entonces, en la combinación de ambos, colonialidad y patriarcado, que se explica el estatus y el uso otorgado al cuerpo femenino en la promoción turística de una periferia colonial. Esta última, a su vez, con fama mundial de ser un paraíso natural, tal es el caso de Costa Rica.

El hecho de que el cuerpo femenino tenga el mismo estatus, indistintamente del tipo de sitio web o institución que promocione productos relacionados con el sol y la playa, es también una muestra de lo arraigada y lo asentada que está su mercantilización, como parte inherente de la promoción turística.

Cuando se habla de las relaciones desiguales que se establecen, por un lado, entre entes desarrolladores, inversionistas y élites locales; y por otro, entre pobladores y recursos naturales del destino turístico, no se deben considerar únicamente los análisis economicistas y cuantitativos (sobre todo en turismo residencial y de sol y playa). Es necesario ir más lejos, hasta abarcar lo que algunos teóricos de la decolonialidad llaman matriz colonial de poder y lo que la teoría feminista denominó patriarcado. En ese sentido, cada acción, cada concepción y cada decisión, por pequeña que sea al momento de presentar un producto turístico, está enraizada en todo un sistema de pensamiento, en una batería de creencias y nociones que se dan por sentadas y que no se 
cuestionan; pero que reproducen relaciones de poder y traen consecuencias a aquellos que entran en contacto con lo que se exhibe.

Muchas de las críticas, bastante acertadas, que hacen estudiosos del turismo a ciertos tipos de explotación, como las expuestas al inicio de este trabajo, no pueden realmente generar una transformación hasta que todos los detalles sean considerados con atención. Un cambio de paradigma tiene que estar sustentado por un cambio de imaginación y representación. Por lo tanto, es necesario tener presente el poder de la narración y la enunciación, asimismo, tomar en cuenta los efectos que se obtienen al negarle a un sujeto el derecho de narrarse y verse con voz y ojos propios.

Edward Said, al respecto, menciona que no puede existir un sistema de representación en el cual los hechos hablen por sí mismos, sin toda una narrativa socialmente aceptable que los absorba, los sustente y los distribuya (1982). Esa narrativa socialmente aceptable, imbuida en el colonialismo y en el androcentrismo, es la que se debe cuestionar. De esa forma, cada uno podrá verse con sus propios ojos y, en el caso de las mujeres, podrán verse como sujetos autónomos, cuyos cuerpos no están en venta, ni son señuelos de la mirada heteronormativa, la cual ostenta un poder económico y epistemológico que los reclama como de su propiedad y a su disposición. 
Aledo, A. (2008). De la tierra al suelo: la transformación del paisaje y el nuevo turismo residencial. Arbor: Ciencia, Pensamiento y Cultura, 184(729), 99-113. Recuperado de http://arbor.revistas.csic.es/index.php/arbor/article/view/164/164

Bahktin, M. (1981). The Dialogic Imagination: Four Essays. Austin: University of Texas Press.

Beauvoir, S. (2010). The Second Sex. Nueva York: Vintage Books.

Bourdieu, P. (1986). Materiales de sociología crítica: Notas sobre la percepción social del cuerpo. Madrid: Ediciones La Piqueta.

Butler, J. (1993). Cuerpos que importan: sobre los límites materiales y discursivos del sexo. Buenos Aires: Paidós.

Cañada, E. (2011). Conflictividad turística en Centroamérica. En E. Cañada y M. Blázquez (Eds.), Turismo Placebo: Nueva colonización turística (pp. 163-208). Managua: EDISA.

Carson, F. y Pajaczkowska, C. (2000). Feminist Debate and Fine Art Practices. Edinburgh: University Press Ltd.

Echtner, C. y Pushkala, P. (2003). The Context of Thirld World Tourism Market. Annals of Tourism Research, 30(3), 669-683.

Lipsitz, S. (1993). The Lenses of Gender. New Haven: Yale University Press.

Lynch, D. (2005). Advertising Motherhood: Image, Ideology and Consumption. Berkeley Journal of Sociology, 49, 32-47.

Mignolo, W. (2007). La colonialidad: la cara oculta de la modernidad. Recuperado de http://www.macba.es/PDFs/walter_mignolo_modernologies_cas.pdf 
Eva en el Paraíso: La construcción y representación...

Molina, S. y Rodríguez S. (1991). Planificación integral del turismo: Un enfoque para Latinoamérica. México: Trillas.

Mujeres adornando el paisaje para promocionar playas costarricenses. [Figura 1]. Recuperado de www.santateresa.com/beaches/, www.montezumabeach.com, www.forbes.com y www.flightofspice.com/2016/01/19/travelguide-manuel-antonio-costa-rica/

Munshi, I. (2006). Tourism Processes and Gender Relations: Issues for Exploration and Intervention. Economic and Political Weekly, 41(42), 4461-4468.

Pritchard, A. y N. Morgan. (2000). Privileging the Male Gaze. Annals of Tourism Research, 27(4), 884-905.

'Pro'Sobopha, M. (2005). The Body: Gender and the Politics of Representation. Agenda: Empowering Women for Gender Equity, 63(2), 117-130.

Rando, F. (1991). The Essential Representation of Woman. Art Journal, $50(2), 48-52$.

Román, M. (2011). Mercados de tierra y turismo residencial: Propuestas metodológicas a partir de caso centroamericano. En E. Cañada y M. Blázquez (Eds.), Turismo Placebo: Nueva colonización turística (pp. 103-134). Managua: EDISA.

Said, E. (1982). The Edward Said Reader. Nueva York: Vintage. 
Spencer, H. (1852). A Theory of Population Deduced from the

General Law of Animal Fertility. Westminster Review, 57, pp. 468-501.

\section{¿Cómo citar este artículo?}

Barboza, E. (Julio-diciembre, 2016). Eva en el Paraíso: La construcción y representación del cuerpo femenino en la playa como espacio turístico en Costa Rica. Revista humanidades, 6(2), 1-30. doi: dx.doi.org/10.15517/h.v6i2.26741 